\title{
The Extracorporeal Life Support Organization Registry: update and perspectives
}

\author{
Roberto Lorusso ${ }^{1}$, Peta Alexander ${ }^{2,3}$, Peter Rycus ${ }^{4}$, Ryan Barbaro ${ }^{5}$ \\ ${ }^{1}$ Cardio-Thoracic Surgery Department, Heart \& Vascular Centre, Maastricht University Medical Centre, Maastricht, The Netherlands; ${ }^{2}$ Department \\ of Cardiology, Boston Children's Hospital, ${ }^{3}$ Department of Pediatrics, Harvard Medical School, Boston, Massachusetts, USA; ${ }^{4}$ Extracorporeal Life \\ Support Organization, Ann Arbor, Michigan, USA; ${ }^{5}$ Department of Pediatrics, C.S. Mott Children's Hospital, Ann Arbor, Michigan, USA \\ Correspondence to: Roberto Lorusso, MD, PhD. Cardio-Thoracic Surgery Department, Heart \& Vascular Centre, Maastricht University Medical \\ Centre, P. Debyelaan 12, 6221 AZ, Maastricht, The Netherlands. Email: roberto.lorussobs@gmail.com.
}

\begin{abstract}
From the birth of the Extracorporeal Life Support Organization (ELSO) Registry in 1989, collecting the most relevant information about extracorporeal life support (ECLS) for refractory cardiac or respiratory compromise, was created in order to provide useful information and benchmark for ECLS users. Throughout the years, the Registry has continuously developed, achieving in 2018 more than 100,000 patients included with almost 500 ELSO centers around the world. Based on the relevance and impact of database analysis, and due to the growing need for more advanced and high-quality clinical investigations, the ELSO Registry is under substantial re-engineering which will allow and provide the ELSO members and the scientific community an enhanced scientific tool to elucidate various aspects of the ECLS settings, including trends and disease-specific information, to perform benchmarking about our own results and outcomes as compared to regional or worldwide results, and to provide an invaluable source of data for clinical investigations.
\end{abstract}

Keywords: Registry; Extracorporeal Life Support Organization (ELSO); extracorporeal membrane oxygenation (ECMO); extracorporeal life support (ECLS)

Submitted Sep 24, 2018. Accepted for publication Oct 25, 2018.

doi: 10.21037/acs.2018.11.03

View this article at: http://dx.doi.org/10.21037/acs.2018.11.03

\section{Introduction}

The Extracorporeal Life Support Organization (ELSO) and its Registry were created to facilitate the advancement of extracorporeal life support (ECLS) care through research and benchmarking. The first ELSO Registry Report was published in 1988 (1) and described the outcomes of 715 neonates cared for in 18 institutions, as well as each center's learning curve. Now, thirty years later, more than 10,000 patients are entered into the ELSO Registry annually, from almost 500 active centers in 60 countries, with the ELSO Registry containing over 100,000 patients (2). As the ELSO Registry has grown in cumulative and annual volume, it has also evolved in its organization and infrastructure. The ELSO Registry is currently divided into three subcommittees with distinct aims: the ELSO Registry Development Committee, the ELSO Scientific Oversight Committee and the Registry Quality Committee.

\section{The ELSO Registry Development Committee}

The ELSO Registry Development Subcommittee aims to improve the validity, value and efficiency of data collection in the ELSO Registry. The ELSO Registry Development Subcommittee has published the database definition manual. The first draft of trauma addenda [and updates to existing cardiac, and extracorporeal cardiopulmonary resuscitation (ECPR)] addenda are under revision. There is a formalized team that responds to Registry questions and evaluates the need for updates to Registry Database Definitions every six months. 


\section{Validity}

To ensure validity of the data collection, ELSO has partnered with industry leaders to ensure at the point of entry ELSO employs real-time validity for all entries. ELSO has a database definitions manual which defines every data field and provides detailed practical examples. To minimize the burden of data collection, the database has published a minimum dataset, which includes variables incorporated into extracorporeal membrane oxygenation (ECMO)-specific risk adjustment model as well as critical outcomes. To ensure uniformity in the understanding of data fields, there is a database entry exam that will be required for all new centers and for ELSO data entry personnel in 2019. Finally, ELSO has piloted the external validation and plans the external validation of a $10 \%$ random selection of patients at centers receiving site visits for their center of excellence application. ELSO plans to execute a $10 \%$ validation of all centers by 2021 .

\section{Value}

ELSO also seeks to ensure the data being collected is valuable to centers. This means that the data collected must be accurate and informative without being overly burdensome in its collection. To achieve this, the Registry has maintained the core Registry data elements in the same format for the last 30 years, but we have also recognized as the field evolves, so do data collection needs. The ELSO Registry Development Subcommittee meets quarterly to evaluate if new fields need to be added to the registry database collection or if existing database definitions need refinement for clarity. This process is based on user feedback. When data collection is only needed for a subsample of the ECMO community, an ELSO Registry Addendum can be proposed. An addendum can be created when a group of $10 \%$ of ELSO centers commit to collecting data for two years and when a database definitions manual has been established that collects reliable, reproducible data and funding for creation of the addenda has been secured. Addenda can be established for quality assurance, research or device development.

\section{Efficiency}

ELSO seeks to facilitate accurate, efficient data collection. Many centers use internal programs that automatically extract data from the medical record. ELSO has built an XML-based platform that allows this information to be supplemented with manual data collection and to be uploaded into the Registry after the data has been assessed with real-time validation checks and for completeness of the minimal dataset. ELSO is also developing and maintaining relationships with overlapping registries to ensure data alignment and ease of data collection. In addition, ELSO is establishing relationships with systems integrators that allow for data collection into one platform that populates overlapping data fields.

\section{Responsive}

ELSO members often have questions about how uncommon conditions perform on ECMO. In order to provide timely and responsive feedback based on the ELSO Registry, ELSO has developed the ELSO outcome reporter. The ELSO outcome reporter enables members to type in any diagnosis, procedure age group and support type and immediately receive back patient survival and average ECMO support time for the entire ELSO Registry, within the last five years (Figure 1).

\section{ELSO Registry Scientific Oversight Committee}

The ELSO Registry Scientific Oversight Committee aims to facilitate and promote the development of scientific research from the ELSO Registry for ELSO member scientists. The ELSO Registry has long been used to facilitate member-driven questions and since 2006 the ELSO Registry has been used in over 100 publications, including New England Fournal of Medicine, American fournal of Respiratory Critical Care Medicine, Circulation, Critical Care Medicine, Intensive Care Medicine (3-24) and Nasr ASAIO.

The Scientific Oversight Committee also oversees ELSO publications, including the ELSO Registry Reports. The ELSO Reports are authored by international experts in the field who are familiar with the ELSO database. The ELSO Scientific Oversight Committee oversees data requests every month, with a diverse group of participants including: cardiothoracic surgeons, emergency room physicians, pulmonologists, anesthesiologists, trauma surgeons, pediatric surgeons, pediatric cardiologists, pediatric intensivists, neonatologists and perfusionists from all over the world. Data requests are reviewed by a primary reviewer who assess the merits, scientific plan 


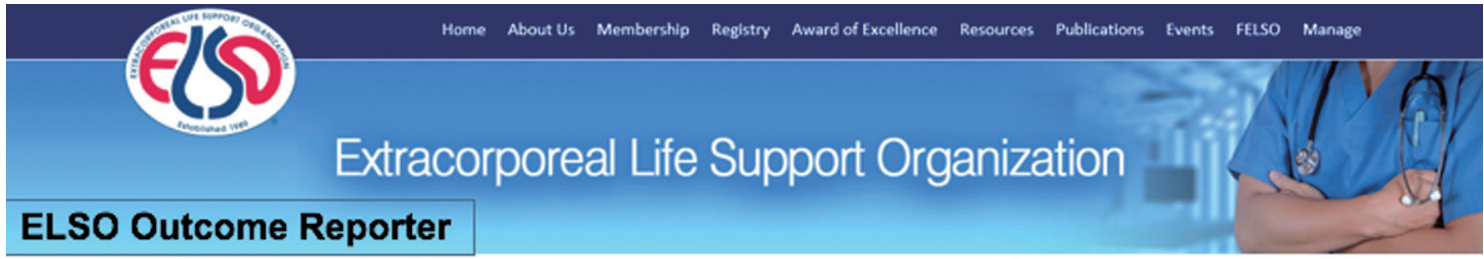

Step 1: select any applicable age group, support type and mode of ECMO support

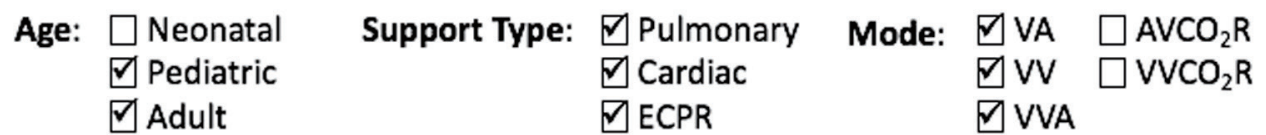

Step 2: enter text for the diagnosis of interest and click the desired codes List of ICD 10 Codes

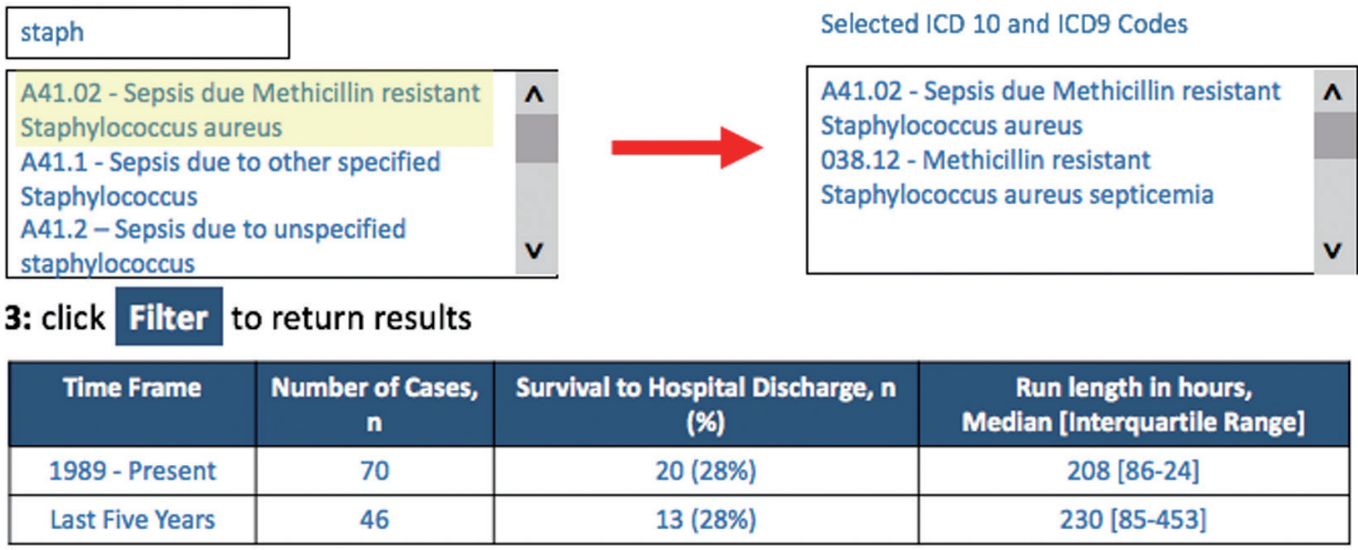

Figure 1 A representative page of the new ELSO Registry which may allow searches linked to specific etiology codes, with immediate information regarding number os cases present in the Registry, in-hospital survival rate, and ECLS duration time (hours). ELSO, Extracorporeal Life Support Organization; ECLS, extracorporeal life support.

and uniqueness from ongoing studies. The primary reviewer presents the study to the Scientific Oversight Committee who then evaluate the study and reach agreement to approve or decline the study. The approved data requests are publicly displayed on the ELSO website to continuously inform the scientific community about ongoing ELSO Registry-based research. With the evolution of more sophisticated study proposals requiring large portions of the ELSO Registry, more stringent guidelines are applied, including statistical analysis plan review, facilitated through a Large Datasets Request Committee which meets quarterly. Recently, a review of important publications obtained by using the ELSO Registry database from 2006 to 2017 has been published (25).

If a data request is approved, the prospective scientist is granted data for 1 year, the approved data request is placed on the ELSO website and if substantial progress towards publication is not achieved within the year, then the data can be re-released to a group of investigators. This process is driven by policies which are published on the ELSO website.

\section{ELSO Registry Quality Committee}

The Registry Quality Committee aims to refine tools and measures to assess the center specific ECMO outcomes through tools such as the ELSO Quality Reporting Platform that benchmark ELSO Member Center performance to peer institutions. ELSO is partnered with ArborMetrix, the leading provider of clinically rich, real-time analytics, to develop the ELSO Quality Reporting Platform (Figure 2). The ELSO Quality Reporting Platform allows members to track outcomes and deliver quality care in a way they have not before. With this application, centers can track 


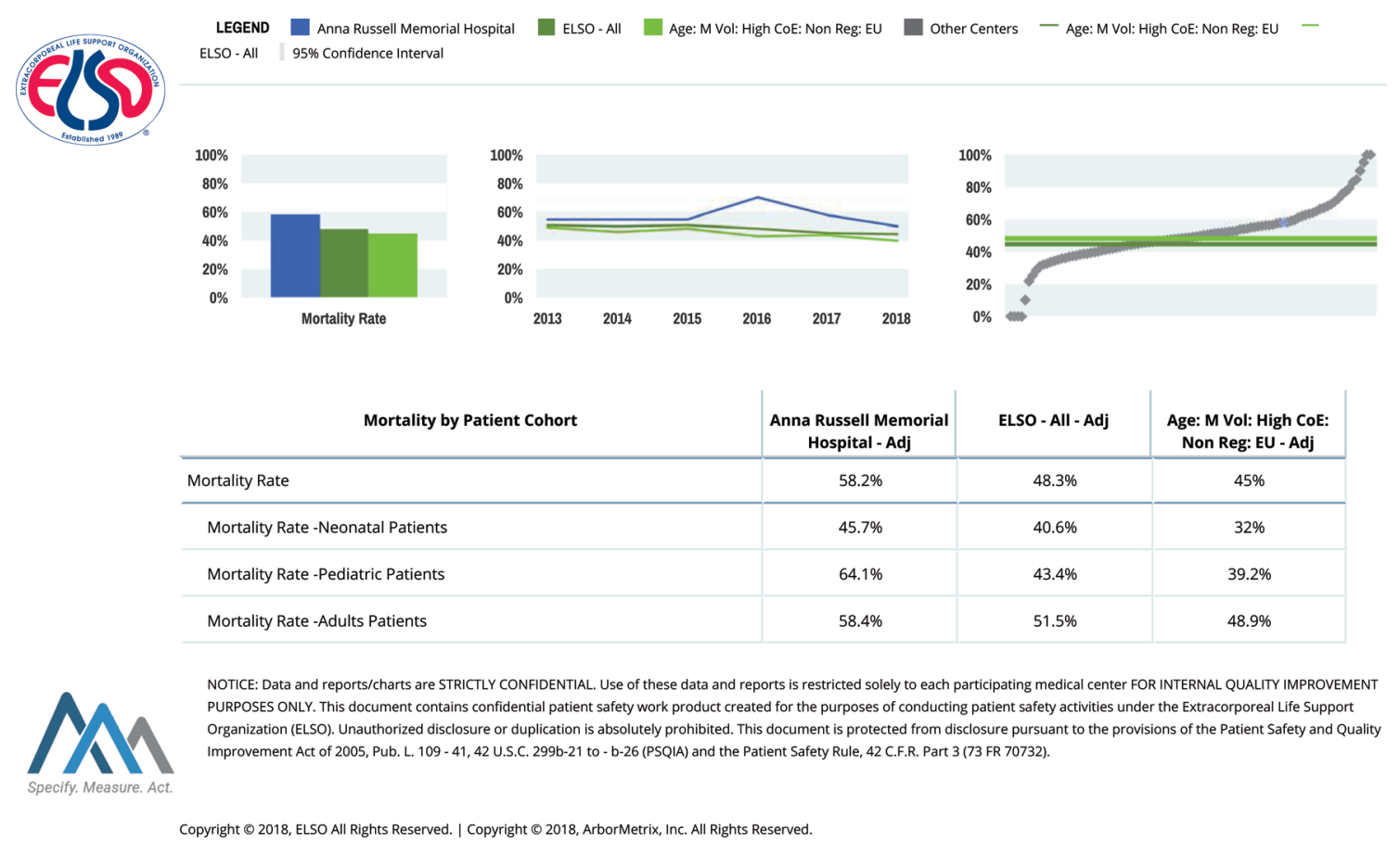

Figure 2 The figure shows the ELSO Quality Reporting Platform. This internet-based system allows the member ELSO center to at-glance evaluate the overall situation per indication and procedure regarding all ECMO aspects, including survival or complications and other ECLSbased variables, and the center performance in the same fields. This will allow real-time assessment and benchmark of own activities and outcomes. ELSO, Extracorporeal Life Support Organization; ECMO, extracorporeal membrane oxygenation; ECLS, extracorporeal life support.

center-based performance across time and compare performance to peer centers using metrics such as survival, major complications, minor complications and length of stay. Centers can tailor peer group comparisons based on volume, patient mix, ELSO Center of Excellence status and ELSO World Regions. Risk adjustment is based on a combination of published ECMO risk adjustment models (RESP, SAVE, PREP, Ped-RESCUES, Neo-RESCUERS, PIPER) (21-24) and ArborMetrix built risk adjustment models where populations are unavailable (variable missing $<10 \%$ of time, plausible meaningful candidate variable). Webinars have been and will be carried out to illustrate and guide about use and potentials.

The future steps of the ELSO Quality Reporting Platform will inform pertinent topics for official releases, launch device developer platform and initiate teams to evaluate current quality metrics and develop future ones. Finally, efforts will be carried out to execute prospective funded prospective research through ELSO. The ELSO Registry to meet regulatory body standards for approval and post-market surveillance of extracorporeal devices.

\section{Contributors to the ELSO Registry}

Many specialist physicians, surgeons, nurses and allied health specialists from around the world have provided their services and contributions to support this important endeavor to build a new and more efficient ELSO Registry. Periodical reporting, including specific fields, such as Cardiac, Respiratory or ECPR, will be realized every 3 years, in order to release up-to-date information about etiology-based results and outcomes, aiming at a better ECLS and non-ECLS communication.

\section{Acknowledgements}

This is to acknowledge the contribution of all ELSO centers and the professionals who make up the ELSO community. Their action, invaluable work and data collection has been critical for the ELSO Registry growth and success, as well as for the future performance and improvement. A sincere thanks and deep gratitude are a small appreciation for the past, present and upcoming support to such a scientific 
initiative in a challenging medical field. Last, but not least, a thought goes to all the patients who were treated always with a strive for life against critical illnesses and pending death.

\section{Footnote}

Conflicts of Interest: The authors have no conflicts of interest to declare.

\section{References}

1. Toomasian JM, Hsu LC, Hirschl RB, et al. Evaluation of Dura o II heparin coating in prolonged extra- corporeal membrane oxygenation. ASAIO Trans 1988;34:410-4.

2. Tracy TF Jr, DeLosh T, Bartlett RH. Extracorporeal Life Support Organization 1994. ASAIO J 1994;40:1017-9.

3. Conrad SA, Rycus PT, Dalton H. Extracorporeal Life Support Registry Report 2004. ASAIO J 2005;51:4-10.

4. Thiagarajan RR, Barbaro RP, Rycus PT, et al. ELSO Member Centers: Extracorporeal Life Support Organization Registry International Report 2016. ASAIO J 2017;63:60-7.

5. Barbaro RP, Paden ML, Guner YS, et al. ELSO member centers: Pediatric Extracorporeal Life Support Organization Registry International Report 2016. ASAIO J 2017;63:456-63.

6. Thiagarajan RR, Laussen PC, Rycus PT, et al. Extracorporeal membrane oxygenation to aid cardiopulmonary resuscitation in infants and children. Circulation 2007;116:1693-700.

7. Brogan TV, Thiagarajan RR, Rycus PT, et al. Extracorporeal membrane oxygenation in adults with severe respiratory failure: A multi-center database. Intensive Care Med 2009;35:2105-14.

8. Almond CS, Singh TP, Gauvreau K, et al. Extracorporeal mem- brane oxygenation for bridge to heart transplantation among children in the United States: analysis of data from the Organ Procurement and Transplant Network and Extracorporeal Life Support Organization Registry. Circulation 2011;123:2975-84.

9. Fraser CD Jr, Jaquiss RD, Rosenthal DN, et al. Berlin Heart Study Investigators: Prospective trial of a pediatric ventricular assist device. N Engl J Med 2012;367:532-41.

10. Polito A, Barrett CS, Wypij D, et al. Neurologic complications in neonates supported with extracorporeal membrane oxygenation. An analysis of ELSO registry data. Intensive Care Med 2013;39:1594-601.

11. Barbaro RP, Odetola FO, Kidwell KM, et al. Association of hospital-level volume of extracorporeal membrane oxygenation cases and mortality. Analysis of the extracorporeal life support organization registry. Am J Respir Crit Care Med 2015;191:894-901.

12. Lorusso R, Barili F, Mauro MD, et al. In-hospital neurologic com- plications in adult patients undergoing venoarterial extracorporeal membrane oxygenation: Results from the Extracorporeal Life Support Organization Registry. Crit Care Med 2016;44:e964-72.

13. Lorusso R, Gelsomino S, Parise O, et al. Neurologic injury in adults supported with veno-venous extracorporeal membrane oxygenation for respiratory failure: Findings from the Extracorporeal Life Support Organization Database. Crit Care Med 2017;45:1389-97.

14. Haas NL, Coute RA, Hsu CH, et al. Descriptive analysis of extracorporeal cardiopulmonary resuscitation following out-of-hospital cardiac arrest-An ELSO registry study. Resuscitation 2017;119:56-62.

15. Freeman CL, Bennett TD, Casper TC, et al. Pediatric and neonatal extracorporeal membrane oxygenation: does center volume impact mortality? Crit Care Med 2014;42:512-9.

16. Thiagarajan RR, Brogan TV, Scheurer MA, et al. Extracorporeal membrane oxygenation to support cardiopulmonary resuscitation in adults. Ann Thorac Surg 2009;87:778-85.

17. del Nido PJ, Dalton HJ, Thompson AE, et al. Extracorporeal membrane oxygenator rescue in children during cardiac arrest after cardiac surgery. Circulation 1992;86:II300-4.

18. Baldwin JT, Borovetz HS, Duncan BW, et al. The National Heart, Lung, and Blood Institute Pediatric Circulatory Support Program. Circulation 2006;113:147-55.

19. Ricci $Z$, Amodeo A. Prospective trial of a pediatric ventricular assist device. N Engl J Med 2012;367:2159-60.

20. Hardart GE, Hardart MK, Arnold JH. Intracranial hemorrhage in premature neonates treated with extracorporeal membrane oxygenation correlates with conceptional age. J Pediatr 2004;145:184-9.

21. Schmidt M, Burrell A, Roberts L, et al. Predicting survival after ECMO for refractory cardiogenic shock: The survival after veno-arterial-ECMO (SAVE)-score. Eur Heart J 2015;36:2246-56.

22. Barbaro RP, Boonstra PS, Paden ML, et al. Development and validation of the pediatric risk estimate score for children using extracorporeal respiratory support (PedRESCUERS). Intensive Care Med 2016;42:879-88.

23. Schmidt M, Bailey M, Sheldrake J, et al. Predicting survival 
after extracorporeal membrane oxygenation for severe acute respiratory failure. The Respiratory Extracorporeal Membrane Oxygenation Survival Prediction (RESP) score. Am J Respir Crit Care Med 2014;189:1374-82.

24. Schmidt M, Zogheib E, Rozé H, et al. The PRESERVE mortality risk score and analysis of long-term outcomes after extracorporeal membrane oxygenation for severe acute respiratory distress syndrome. Intensive Care Med 2013;39:1704-13.

25. Nasr VG, Raman L, Barbaro RP, et al. Highlights from the Extracorporeal Life Support Organization Registry. ASAIO J 2018. [Epub ahead of print].

Cite this article as: Lorusso R, Alexander P, Rycus P, Barbaro R. The Extracorporeal Life Support Organization Registry: update and perspectives. Ann Cardiothorac Surg 2019;8(1):93-98. doi: 10.21037/acs.2018.11.03 